
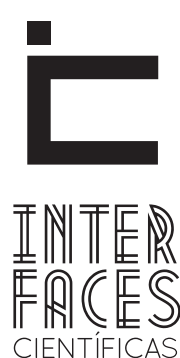

EDUCAÇÃO

ISSN IMPRESSO 2316-333X

E-ISSN 2316-3828

DOI-10.17564/2316-3828.2017v5n3p43-52

\title{
A CONSTITUIÇÃO DA PROFISSIONALIDADE DOCENTE NA EDUCAÇ̃̃O SUPERIOR
}

\author{
THE CONSTITUTION OF TEACHING PROFESSION IN HIGHER EDUCATION \\ LA CONSTITUICIÓN DE LA PROFESIONALIDAD DOCENTE EN LA EDUCACIÓN SUPERIOR
}

\section{RESUMO}

Esse artigo almeja uma reflexão acerca da constituição da profissionalidade do docente que atua na Educação Superior em instituições no Brasil. Um breve cenário histórico sobre a constituição do ensino Superior brasileiro foi desenvolvido, destacando alguns viesses da história mundial que perpassam a formação do docente que trabalha nesse contexto. Destacamos ainda, o conceito de profissionalidade e como a pedagogia universitária prepara esse docente, es- pecificamente através de formação continuada. Além disso, apresentamos as diversas atribuições e significados que são atribuídos a esse profissional.

\section{PALAVRAS-CHAVE}

Profissionalidade docente. Formação de professores. Educação superior. 


\section{ABSTRACT}

This article reflects on the constitution of teaching profession in higher education in Brazil. A brief historical setting on the Brazilian higher education constitution was developed, highlighting some of the perspectives of world history that permeate the formation of the teacher who works in this context. We also highlight the concept of profession and how university pedagogy prepares this teacher, specifically through

\section{RESUMEN}

Este artículo tiene como objetivo reflexionar sobre la formación de profesionalidad de los profesores que participan en las instituciones de educación superior en Brasil. Se desarrolló una breve reseña histórica sobre la formación de la Educación Superior brasileña, destacando algunos puntos de la historia mundial que pasan por la formación de los profesores que trabajan en este contexto en Brasil. También señalamos el concepto de profesionalidad y cómo la enseñanza continuing education. Furthermore, we introduce the various assignments and meanings that are assigned to this professional.

\section{KEYWORDS}

Teaching profession. Teacher formation. Higher education.

universitaria prepara el docente, en particular, mediante la formación continua. Además, se presentan las diversas funciones y significados que se atribuyen a este profesional.

\section{PALABRAS CLAVE:}

Profesionalidad Docente. Formación de Profesores. Educación Superior. 


\section{INTRODUCÇÃO}

As instituições de Educação Superior no Brasil voltam a sua atenção para a Política Nacional de Educação homologada pelo Ministério da Educação (MEC). Em meio à globalização e ao capitalismo vigente no país, essas instituições, veementemente, tentam legitimar-se diante de um contexto multifacetado, no qual missão, valores e cultura organizacional são permeados por diretrizes, normas, portarias, leis, mercado competitivo, gerando preocupação constante em destaque na área Educacional.

Delors (1999, p. 9), em relatório à Organização das Nações Unidas para Educação, Ciência e Cultura (UNESCO), afirmou que "a competição impele um grande número de responsáveis a esquecer da missão que consiste em fornecer a cada ser humano os meios para realizar todas as suas potencialidades". Diante de tantas variáveis, que perpassam o funcionamento e a logística das instituições de ensino superior, destacamos os professores, como força matriz que retroalimentará o sucesso e a consolidação da instituição e os estudantes que serão o público-alvo e objetivo maior. Uma vez que são os estudantes e os professores atores sociais que representam a principal essência da instituição.

Além disso, inicialmente é importante destacar como entendemos a profissionalidade docente como as várias competências e habilidades que devem ser desenvolvidas pelos docentes (MASETTO; GAETA, 2013). Essa relação nos remeteu a uma complexidade, sendo que são as inúmeras demandas que competem ao professor: "cabe também motivar, acompanhar, orientar, conduzir, já não basta 'saber' é preciso enfatizar o preparo pedagógico” (CERONI; CASTANHEIRA, 2012, p. 7). Os autores evidenciam o preparo pedagógico para que os professores compreendam que há um despreparo de muitos docentes universitários e estes não conseguem refletir e avaliar suas próprias práticas.

Este artigo tem como objetivo abordar a construção da profissionalidade do docente que atua na Educação Superior no Brasil. É importante destacarmos o que entendemos por configurações da Educação Superior. Consideramos, aqui, a estruturação que as instituições devem seguir, que são propostas pelo MEC, mas também propomos apresentar o pano de fundo que subjaz as configurações que são pré-definidas pelo Ministério da Educação. Pontuamos alguns aspectos que englobam a educação superior no Brasil: a profissionalização da docência, o teor competitivo e capitalista que atuam direta ou indiretamente nos desempenhos dos alunos e dos professores.

\section{BREVE HISTÓRICO DA EDUCAÇÃO SUPERIOR NO BRASIL}

Tivemos, no início da história da educação brasileira, os catequistas como os primeiros professores do Brasil, com a missão de transmitir conhecimentos religiosos aos índios que aqui viviam. Durante muito tempo da história da educação, a formação profissional do professor se construía "acadêmica e culturalmente, num técnico para transmitir informações aos seus alunos" (SANTOS; ANTUNES, 2013, p. 299). Culturalmente, o ensino superior no Brasil herdou o modelo curricular napoleônico (MASETTO; GAETA, 2013), o qual exigia que o professor formasse profissionais reprodutores de conhecimento e que estivessem aptos a aplicar o conhecimento meramente técnico e operacional, sendo o professor o eixo central do processo de ensino e aprendizagem.

No entanto, mudanças históricas e culturais passaram a exigir novas metodologias de formação profissional, mudando o foco do ensino técnico para o ensino superior. Com o passar dos anos, o processo de avaliação da formação profissional sofreu diversas modificações nos moldes de avaliação do Exame Nacional de Desempenho de Estudantes (ENADE exame que faz parte da política de avaliação e acompanhamento das instituições de ensino superior para credenciamento ou recredenciamento), avaliando se estão de acordo com padrões de qualidade exigidos (MASETTO, 2010). Na atualidade, cabe às instituições de ensino superior formar profissionais com percep- 
ção crítica e que sejam capazes de aplicar na prática as habilidades e competências desenvolvidas durante o curso de formação.

Diante das mudanças no contexto da educação superior, tanto do ensino proposto pelos docentes quanto da aprendizagem que deve ser desenvolvida pelo aluno, foi necessário uma reinvenção na operacionalização do trabalho docente. Foram repensados desde os objetivos educacionais, bem como metodologias de ensino, habilidades para o planejamento de aprendizagens em diferentes contextos (virtuais e profissionais) e cooperação entre os docentes. $\mathrm{O}$ que proporcionou ao docente universitário uma reconfiguração e reinvenção profissional, surgindo, assim, a profissionalidade na docência (MASETTO; GAETA, 2013; LOUREIRO, 2001).

O histórico do ensino superior no Brasil se constituiu por meio da implantação de cursos profissionalizantes que capacitavam a mão de obra local, para atender as demandas do Brasil colonial. Aos poucos emergem cátedras isoladas dos cursos de direito e medicina, na Bahia, Rio de Janeiro, Recife e Manaus (MASETTO; GAETA, 2013; BARROS, 2015; ANTUNES, 2007). Vale ressaltar que apesar do início do ensino superior no Brasil se caracterizar com cursos profissionalizantes, ao longo do tempo esse tipo de ensino foi desvalorizado pela população.

Em contrapartida houve a valorização dos cursos de graduação e licenciatura. No entanto, em meados de 2010 o governo federal constatou a necessidade no mercado de trabalho de técnicos especializados em determinadas áreas. Assim, foi criado pelo Governo Federal, em 2011, o Programa Nacional de Acesso ao Ensino Técnico e Emprego (PRONATEC). Esse programa tende a crescer e a se fortalecer, caso as mudanças que foram propostas em 2016 ao ensino médio sejam aprovadas.

No entanto, retomando a implantação do ensino superior no Brasil, no primeiro momento, os professores eram fidalgos, filhos de portugueses nascidos no Brasil que estudaram e se formaram em Portugal (ANTUNES, 2007). Posteriormente, durante 200 anos no Brasil, eram convidados para ministrar aulas no ensino superior os profissionais que se destacavam, prestando um serviço de qualidade para a sociedade, sendo reconhecido pela população (MASETTO; GAETA, 2013). Dessa forma, para ser professor universitário no Brasil era preciso apenas ter graduação, ser especialista e ter um reconhecimento social.

A globalização foi o grande diferencial do século $X X$, o que propiciou avanços significativos na construção e socialização do conhecimento por meio da inserção da cultura digital mediada pelas tecnologias de informação e comunicação. 0 que favoreceu a expansão da interdisciplinaridade, aumentando, pois, a complexidade na produção do conhecimento, do ser professor e da formação profissional (MASETTO; GAETA, 2013). Esse contexto fomentou mudanças e inovações curriculares, o repensar ser professor, emergindo o conceito de profissionalidade docente. Após o século XX, para ser professor do ensino superior não bastava ter reconhecimento social, era preciso passar por um processo de profissionalização, que discutiremos ao longo deste artigo.

\section{A DOCÊNCIA E A PROFISSIONALIDADE NA EDUCAÇ̃̃O SUPERIOR}

Entendemos por profissionalidade o conjunto de competências, habilidades, conhecimentos e experiências sociais reconhecidas para o exercício de determinado cargo ou função (MASETTO; GAETA, 2013). Tudo o que compõe a execução de determinada função profissional relaciona-se a profissionalidade.

O fato de o termo profissionalidade ter surgido na Itália possibilitou que fosse veementemente discutido na Europa, chegando ao Brasil por influência da literatura francesa. 0 conceito de profissionalidade está associado "às instabilidades e ambiguidades que envolvem o trabalho em tempos neoliberais, e geralmente vem colocado como uma evolução da ideia de qualificação" (LÜDKE; BOING, 2004, p. 1173). De acordo com estes autores, o termo profissionalidade emerge de um contexto social europeu no qual as empresas começam a pensar na importância da des- 
centralização das responsabilidades e dos saberes, no desenvolvimento da produção de serviços, na flexibilidade, favorecimento das interações e da personalização, redução ao máximo do número de funcionários e aumento da qualificação profissional, pró atividade e polivalência, redução da influência sindical e medo do desemprego.

Para Cunha (2015), autor português, a profissionalidade docente remete a funções e competências específicas, tais como: utilizar metodologias interativas, organização pedagógica horizontal, adesão a novas tecnologias em sala de aula, intervenções adaptadas a diferentes realidades socioculturais.

No Brasil, muitas vezes há dissonância entre as grades curriculares e as exigências no mercado de trabalho. A fim de minimizar essas divergências, houve a modificação das Diretrizes Curriculares Nacionais e dos projetos pedagógicos da Educação Superior, o que tornou mais visível e consistente a profissionalidade docente (MASETTO; GAETA, 2013). Após o parecer n ${ }^{0}$ 67/2003 do Conselho Nacional de Educação e da Câmara de Educação Superior, os docentes começaram a participar de modo mais ativo da construção dos conteúdos dos planos de ensino e aprendizagem com base no perfil profissiográfico.

0 perfil profissiográfico consiste em habilidades e competências que são necessárias no cotidiano profissional. As Instituições de Ensino Superior (IES) devem alinhar as grades curriculares e os conteúdos às demandas que são exigidas pelo mercado de trabatho (PELEIAS et. al., 2008). Assim, o profissional deve contemplar as competências, habilidades e comportamentos específicos para exercer a profissão, conectando a teoria à prática profissional, realizando trabalhos de extensão, favorecendo o contato do aluno com a comunidade, além de construir o conhecimento interdisciplinar.

É importante destacar que, diante desse novo cenário na Educação Superior, a profissionalidade do professor se configura por meio da integração entre pesquisadores, professores, alunos, funcionários e técnicos, em que todos passam a ser atores do processo de formação profissional (MASETTO; GAETA, 2013).
0 processo deixa de ser monopolizado pelo Ministério da Educação, tornando-se coletivo. As Universidades passam a atuar de modo mais incisivo, inserindo o professor universitário no processo de reflexão, elaboração e construção das práxis profissionais, fortalecendo a profissionalidade.

Entendemos que esse movimento de coletividade se estende, ainda, para as relações de trabalho e do processo de ensino e de aprendizagem. Os docentes, neste novo modelo, precisam de um tempo para discutir e debater com os outros professores sobre metodologias, conteúdos e ementas das disciplinas, cabendo, também, ao professor promover nos alunos a competência de trabalhar em grupos.

Diante do cenário de mudanças nas diretrizes curriculares do ensino superior, podemos observar mudanças significativas no posicionamento do professor universitário, exigindo-se desse profissional novas competências, o que favorece o fortalecimento da profissionalidade docente. Desse modo, entendemos o conceito de competências por meio da explanação dos autores Masetto e Gaeta (2013, p. 304):

\footnotetext{
Competência sempre tem a ver com um conjunto de saberes, conhecimentos, valores, atitudes, habilidades que nos tornam aptos a tomar decisões de forma correta, pertinente e criativa em nossa vida pessoal, familiar, profissional, social e cidadã.
}

Contudo, ao mencionar a profissionalidade docente emergem novas competências que, de acordo com Cunha (2015), devem ser efetivadas durante a formação do professor para que haja um desenvolvimento profissional e identitário. Entre essas competências, exige-se que o professor execute uma dinâmica pedagógica e profissional no contexto da sala de aula, focando o desenvolvimento comunitário, em que todas as suas convicções, ideologias e rotinas devem ser orientadas por um saber técnico, teórico e reflexivo que ratifica a sua prática, contribuindo para a inserção das práticas profissionais do aluno no contexto sociocultural (CUNHA, 2015), onde a universidade está inserida.

Com o passar dos anos, a exigência curricular na formação do professor universitário aumenta. Torelló 
(2011) separou as competências que os professores universitários precisam desenvolver em duas categorias: as competências de professor e de pesquisador. Para esse autor as competências de professor se subdividem em 34 unidades, que estão distribuídas entre seis categorias de competências relacionadas à função docente. Enquanto que as competências de pesquisadores são subdivididas em 30 unidades, distribuídas em quatro categorias de competências relacionadas à função de pesquisador. Nessa perspectiva, o professor universitário que desempenha a função de pesquisador e professor deve ter um total de 64 unidades de competências.

Neste artigo, iremos nos reportar à categorização de Masetto e Gaeta (2013) que dividiram em três categorias as competências do professor universitário: área do conhecimento, área pedagógica e área política. Sobre a área do conhecimento, para os autores, as IES têm um foco maior na produção de pesquisa e socialização do conhecimento. Assim, para o desenvolvimento dessa competência, deve haver uma inserção em cursos de aperfeiçoamento, Mestrados e Doutorados, além de participação em congressos, eventos acadêmicos e publicação de artigos científicos.

O que aparentemente é apenas uma exigência curricular, na verdade é um modo de formação do professor reflexivo, que pesquisa sobre determinado tema e tem propriedade de expressar seu pensamento e as suas percepções para seus alunos (MASETTO, 2012). Assim, entendemos que há uma ruptura com o modelo napoleônico de ensino.

No entanto, vale ressaltar que apesar de discutirmos a profissionalidade docente, é importante destacar que, de acordo com Morosini e Fernandes (2011), a exigência para atuação na docência do ensino superior tem evidenciado restritivamente o título de graduação ou pós-graduação na especialidade em que o professor atuará, sem que haja uma formação docente especificamente didática. Podemos, assim, observar que:

[...] na medida em que a universidade legitima e habilita a formação de professores para a Educação Básica, mas, contraditoriamente, não habilita a formação do professor universitário, interrogantes nos mobilizam para discutir a Pedagogia Universitária e o investimen- to necessário em estudo e pesquisa, fazendo inserções nas possibilidades de intervenção nas políticas públicas e institucionais. (MOROSINI; FERNANDES, 2011, p. 475).

Todavia, pontuamos uma contradição no cenário educacional. Ao passo que há uma maior exigência de competências, há um desamparo no âmbito da formação profissional didático-pedagógica (TORELLÓ, 2011). Autores como Tardif (2012) atribuem a esse cenário uma crítica em relação à profissionalidade docente. De acordo com o autor, essa formação emerge em meio a uma crise generalizada de identidade profissional, em que epistemologias, valores, ideologias e atitudes de todas as profissões estavam passando por constantes reflexões e atualizações acerca dos posicionamentos éticos profissionais.

Dessa contradição se dá a complexidade com que o tema profissionalidade docente se apresenta. 0 que, a nosso ver, poderá acarretar sobrecarga na atuação dos professores, podendo não saber lidar com as diversas competências que são exigidas. Todavia, de acordo com Morosini e Fernandes (2011), os docentes não passaram por uma formação adequada para gerenciar os diversos saberes, mas precisam estar aptos para desempenhar a função de professor universitário.

Acerca dessas competências pedagógicas que remetem ao professor universitário, Masetto e Gaeta (2013) pontuam diversos tópicos, entre eles destacamos: a construção do plano de aula; a mediação pedagógica na execução do plano de aula; a articulação com outros professores, trabalhando de modo interdisciplinar, contemplando a formação integral do aluno; o planejamento da disciplina e da aula de acordo com as atuais exigências do mercado de trabalho.

A última categoria de competências dos professores universitários proposta por Masetto e Gaeta (2013) é a política. Nessa categoria, o destaque vai para a problematização dos conteúdos ministrados em sala de aula, em rodas de discussão com alunos de modo contextualizado com os problemas atuais da sociedade, sendo realizados debates com grupos de alunos que possuem posicionamentos antagônicos 
para discutirem sobre o mesmo tema, favorecendo o desenvolvimento da argumentação, desenvolvendo estudos de caso, gerando produção de soluções que poderão favorecer comunidades locais, a cidade, o estado ou até mesmo o país, discutindo, também, questões profissionais que poderão ter diversos tipos de encaminhamentos pelo envolvimento de valores éticos, culturais ou sociais.

Enfim, podemos visualizar a amplitude que abrange as competências docentes. O professor universitário, além de dominar as técnicas e saberes da área de atuação específica, ele precisa desenvolver habilidades que transcendem a sua formação profissional. Em meio a essas exigências, entendemos que devemos incluir, ainda, a perspectiva das modificações que ocorreram com a Educação em meio a globalização.

De acordo com Ibarra-Colado (2003), percebe-se que ocorreu uma comercialização de produtos acadêmicos, em que o professor sai do posicionamento de artesão do saber e passa a compor as engrenagens das novas maquinarias da produção do saber. Nesse contexto, compreendemos que artigos científicos, pesquisas, livros, capítulos de livro, tornam-se o capital acadêmico. Bernardo (2014) ressalta que muitas vezes a pesquisa vira um objeto de encomenda de empresas, órgãos governamentais.

Com isso, aquele espaço universitário que proporcionava discussão, construção do conhecimento, autorregulado pela reflexão, autonomia e liberdade de ideias, dá lugar à produção acadêmica em série, aos artigos científicos, que muitas vezes trabalham temas de modo muito pontual (BLANCH-RIBAS; CANTERA, 2011), favorecendo a compreensão dos clientes (estudantes, empresas, instituições governamentais e não-governamentais) acerca das suas respectivas demandas.

Assim, temos o negligenciamento da essência da universidade defendida pela UNESCO sobre os valores da cultura universitária, tal como "a universalidade do saber, o humanismo, iluminismo e crítica social, autonomia e liberdade" (BLANCH-RIBAS; CANTERA, 2011, p. 518). Valores esses que são, na atualidade, postos em segundo plano, preservando a lógica da globalização e do capitalismo.
No Brasil, a Coordenação de Pessoal de Nível Superior (CAPES) espelhou o modelo de avaliação dos docentes que atuam em pós-graduação stricto-sensu no modelo americano que tem como base o quantitativo de produções acadêmicas (BERNARDO, 2014). Muitos desses professores, além da atuação em Mestrados e Doutorados, lecionam na graduação. Com isso, entendemos que pode haver, em alguns momentos, uma desumanização do docente, tanto no processo formativo, quanto na atuação profissional.

Como são avaliados pela capacidade de produção massificada, muitas vezes não têm tempo para se dedicar à didática, às novas metodologias de ensino $\mathrm{e}$ à relação professor-aluno. Além disso, os critérios de avaliação das universidades no Brasil, homologados pelo MEC, referem-se a uma parte significativa de professores que têm os cursos de mestrado e doutorado, mantendo uma carga horária integral e tendo produções acadêmicas. Fávero e Pasinato (2013) questionam: caso não houvesse esse critério de avaliação, será que as universidades iriam focar na pesquisa?

Em paralelo, podemos observar que nos cursos de licenciatura, a pesquisa científica e a formação do professor de ensino médio surgem de modo pontual em cursos de algumas faculdades (OLIVERI; COUTRIM; NUNES, 2010). Com isso, os próprios cursos de licenciatura negligenciam a formação e atuação do professor-pesquisador e produtor do conhecimento no âmbito do Ensino Médio. Ainda percebemos que na área da Educação há uma cristalização do professor como reprodutor do conhecimento. Muito embora, destacamos que a pesquisa é um poderoso elo, que vincula professores e alunos a solucionarem problemas atuais da comunidade (FÁVERO; PASINATO, 2013), possibilitando ao professor ser posicionado como produtor do conhecimento.

Logo, entendemos que a pesquisa se concretiza na formação do professor universitário, compondo um dos aspectos da profissionalidade, sendo inexpressiva durante a atuação do professor do Ensino Médio. No entanto, vale ressaltar que os discentes dos cursos de licenciatura que tiveram a vivência como alunos de iniciação científica durante a graduação, possuem 
uma maior possibilidade de se distanciar da Educação Básica e do ensino médio e passam a se constituir como pesquisadores e a direcionar a formação para atuação no ensino superior.

\section{CONSIDERAÇÕES FINAIS}

Este artigo explanou sobre a construção da profissionalidade do docente que atua na Educação superior. Essa construção perpassa as exigências formais do MEC e dos valores institucionais. Além disso, foram discutidas as inúmeras atribuições que compõem a docência, a formação para a pesquisa, por meio dos cursos de mestrado e doutorado, a construção democrática dos Projetos Pedagógicos dos Cursos, a vinculação entre alunos, professores e a comunidade, além da inserção na produção massificadora e alienante da produção científica, seguindo o modelo norte-americano de produção acadêmica, em detrimento, na maioria, das vezes de uma formação integral do ser com vistas a licenciatura, a didática de ensino e o fazer pedagógico.

\section{REFERÊNCIAS}

ANTUNES, Mitsuko Aparecida Makino. A psicologia no Brasil: leitura histórica sobre sua constituição. 5.ed. São Paulo: Educ, 2007.

\section{BARROS, Lívia de Melo. Os significados da formação}

do ser psicólogo: das crenças culturais as práticas psicológica. Alemanha: Novas Edições Acadêmicas, 2015.

BERNARDO, Marcia Hespanhol. Produtivismo e precariedade subjetiva na universidade pública: o desgaste mental dos docentes. Psicologia \&

Sociedade; 26(n. spe.), p.129-139, 2014.

BLANCH-RIBAS, Josep Maria; CANTERA, Leonor M. Espinosa. La nueva gestión pública de universidades y hospitales: aplicaciones e implicaciones. In E. Agulló, J. L. Álvaro, A. Garrido, R. Medina, \& I.
Schweiger (Eds.), Nuevas formas de organización del trabajo y la empleabilidad. Oviedo, Universidad de Oviedo, p.515-534, 2011.

CERONI, Mary Rosane; CASTANHEIRA, Ana Maria Porto. Docência universitária: algumas reflexões sobre o desenvolvimento profissional do professor. Em: "Aprendizagem e desenvolvimento profissional na docência universitária”. Revista Pandora Brasil, n.49, dezembro de 2012.

CUNHA, António Camilo Ser professor: bases de uma sistematização teórica. Chapecó: Argos, 2015.

DELORS, Jacques. Educação: um tesouro a descobrir. 3.ed. SP: Cortez, 1999.

FÁVERO, Altair Aberto; PASINATO, Darciel. O docente universitário como profissional pesquisador de sua própria prática. Revista Contrapontos - Eletrônica, v.13, n.3, p.195-206, set-dez. 2013.

IBARRA-COLADO, Eduardo. Capitalismo académico y globalización: la universidad reinventada. Educação e Sociedade, v.24, n.84, p.1059-1067, 2003.

LÜDKE, Menga; BOING, Luiz Alberto. Caminhos da profissão e da profissionalidade docentes. Educação Sociedade, Campinas, v.25, n.89, p.1159-1180, setdez. 2004.

MASETTO, Marcos Tarcísio. 0 professor na hora da verdade. São Paulo: Avercamp, 2010.

MASETTO, Marcos Tarcísio. Competência pedagógica do professor universitário. 2.ed. São Paulo: Summus, 2012.

MASETTO, Marcos Tarcísio; GAETA, Cecilia. A docência com profissionalidade docente. Brazilian

Geographical Journal: Geosciences and Humanities research medium, Ituiutaba, v.4, Special Issue 1, p.299-310, jul-dez. 2013. 
MOROSINI, Marília Costa; FERNANDES, Cleoni Maria Barbosa. Educação superior: universidade e o projeto de formação cidadã. Educação, Santa Maria, v.36, n.3, p.465-482, set-dez. 2011.

OLIVERI, Andressa Maris Rezende; COUTRIM, Rosa Maria da Exaltação; NUNES, Celia Maria. Como se forma o professor pesquisador? Primeiras aproximações a partir de um estudo de caso.

Educação em Perspectiva, Viçosa, v.1, n.2, p.293311, jul-dez. 2010.

PELEIAS, Ivam Ricardo et al. Identificação do perfil profissiográfico do profissional de contabilidade requerido pelas empresas, em anúncios de emprego na região metropolitana de São Paulo. Revista de Administração e Contabilidade da Unisinos, v.5, n.2, p.131-141, maio-ago. 2008.
SANTOS, Bettina Steren; ANTUNES, Denise Dalpiaz. Formação docente: processos motivacionais e subjetividade. In: BEZERRA, A.A.C.; NASCIMENTO, M.B.C. (Org.). Educação e formação de professores: questões contemporâneas. Fortaleza: UFC, 2013.

\section{TARDIF, Maurice. Saberes docentes e formação} profissional. 14.ed. Petrópolis- RJ: Vozes, 2012.

TORELLÓ, Òscar Mas. El profesor universitario: sus competencias y formación. Professorado. Revista de currículum y formación del professorado, v.5, n.3, dezembro, 2011. 
